\title{
PROPOSTA DE EXPANSÃO DA CLASSE ESPIRITISMO NA CLASSIFICAÇÃO DECIMAL DE DEWEY
}

\author{
Marcos Luiz Cavalcanti de Miranda ${ }^{1}$ \\ Universidade Federal do Estado do Rio de Janeiro \\ mlmiranda@unirio.br \\ Fernanda de Moura Caban ${ }^{2}$ \\ Universidade Federal do Estado do Rio de Janeiro \\ demouracaban@gmail.com
}

\begin{abstract}
Resumo
Propõe a expansão da classe Espiritismo na Classificação Decimal de Dewey. Justifica a proposta devido ao grande número de adeptos e a produção literária espírita. Evidencia que o Espiritismo é a oitava religião com mais praticantes no mundo e a terceira no Brasil. Apresenta a importância da doutrina espírita ao redor do mundo e no Brasil. Utiliza a teoria proposta por Vanda Brougthon para religião e acrescenta as facetas ciência, filosofia, religião e aspectos gerais da Doutrina Espírita. Analisa propostas de expansão de classes existentes e elabora uma revisão de literatura acerca da história do Espiritismo. Utiliza a metodologia de Barité para modificação de esquemas de classificação. Os termos foram coletados a partir do tesauro espírita e da obra de referência da Federação Espírita Brasileira, e sistematiza os conceitos hierarquicamente. Propõe a expansão da classe $202-$ Doutrina a partir da identificação e sistematização dos conceitos, colocando-os de forma notacional. Conclui que uma doutrina com tantos adeptos e com uma grande produção literária deve ser representada adequadamente na Classificação Decimal de Dewey e que a mesma oferece pouco espaço de representação na classe 200 para as diversas religiões praticadas no mundo.
\end{abstract}

Palavras-chave: Espiritismo. Doutrina. Classificação Decimal de Dewey - Expansão de classe.

\section{EXPANSION PROPOSAL OF THE SPIRITISM CLASS IN THE DEWEY DECIMAL CLASSIFICATION}

\begin{abstract}
The research proposes the expansion of the class of Spiritism in the Dewey Decimal Classification. Judges the proposal due to the large number of followers and the spiritist literary production. Evidence that is the eighth religion with more practitioners in the world and the third in Brazil. Presents the importance of Spiritist doctrine around the world and in Brazil. Uses the theory proposed by Vanda Brougthon for religion and adds the facets science, philosophy, religion and general aspects of the Spiritist Doctrine. Analyzes proposals for expanding existing classes and elaborates a literature review about the history of spiritualism. Uses the Barité methodology to modify classification schemes. Collects the terms from the spiritist thesaurus and the reference work realized by the Brazilian Spiritist Federation and systematizes the concepts hierarchically. Proposes the expansion of class 202 - Doctrine from the identification and systematization of concepts, placing them in a notational way. Concludes that a doctrine with so many adherents and a great literary production should be better represented in Dewey's Decimal Classification. Also mentions that DDC offers little space of representation in class 200 for the diverse religions practiced in the world.
\end{abstract}

Keywords: Spiritism. Doctrine. Dewey Decimal Classification - Expansion of class.

\footnotetext{
${ }^{1}$ Doutor em Ciência da Informação pela Universidade Federal do Rio de Janeiro.

${ }^{2}$ Bacharel em Biblioteconomia pela Universidade Federal do Estado do Rio de Janeiro (UNIRIO). Membro do Grupo de Pesquisa Organização do Conhecimento para Recuperação da Informação (GP/OCRI -UNIRIO).
} 


\section{INTRODUÇÃO}

O presente artigo foi elaborado a partir da pesquisa realizada para uma proposta de expansão da classe Espiritismo na Classificação Decimal de Dewey, motivada devido à falta de representatividade do Espiritismo nos sistemas de organização do conhecimento (SOC) mais utilizados, a exemplo da Classificação Decimal de Dewey (CDD) e da Classificação Decimal Universal (CDU). Neste contexto, indaga-se como uma biblioteca de temática espírita, ou mesmo uma biblioteca geral, mas que possui certa quantidade de obras espíritas classificaria os itens de seu acervo. Sendo assim, as seguintes questões são apresentadas: como seria realizada a representação do conhecimento contido nas obras espíritas com base num esquema de classificação? Todas as obras seriam classificadas em 202 na CDD ou 133.9 na CDU?

Mas, ao recorrer às notações mencionadas, tal fato impossibilitaria uma recuperação da informação eficaz. Como poderia ter toda uma biblioteca, com todo um acervo representado em uma só classe? Sendo identificada a problemática de não haver uma classe mais detalhada abrangendo o Espiritismo e o universo do conhecimento espírita, a representação desse assunto nos SOC mais tradicionais deixa a desejar.

Os sistemas de organização do conhecimento configuram-se como "[...] instrumentos utilizados para organizar e representar o conhecimento [...]” (MORAES; MOREIRA, 2018, p. 959), possibilitando a ordenação das obras nas estantes e a recuperação da informação.

O objetivo geral desse artigo consiste em propor a expansão da classe 202 - Doutrina, na Classificação Decimal de Dewey especificamente para o universo do conhecimento espírita, criando assim, a subclasse 202.5 - Espiritismo e subdivisões que compreendam as facetas religião, filosofia e ciência da Doutrina Espírita. Vale ressaltar que a classe citada já engloba o próprio conceito de Espiritismo em notas, contudo sem uma subclasse específica ou mesmo qualquer subdivisão que apresente o universo do conhecimento espírita, como será evidenciado mais adiante. Os objetivos específicos são mapear conceitos relevantes da Doutrina Espírita; apresentar uma breve história do Espiritismo, seu desenvolvimento e seu panorama no Brasil e analisar a classe 202 - Doutrina na CDD.

Esta pesquisa se justifica, tendo em vista a existência do grande número de espíritas - é a oitava maior religião do mundo, com 13,8 milhões de praticantes, sendo 3,8 milhões somente no Brasil. A cada três espíritas no mundo, um é brasileiro, de acordo com o Censo IBGE 2010 e com a reportagem de Vilaverde (2016) - tal assunto não poderia ser tão pouco representado pelo sistema de organização do conhecimento mais utilizado no mundo, a Classificação Decimal de Dewey. 
Furtado (2001), realizou uma pesquisa nas bibliotecas espíritas na cidade do Rio Grande, localizada no estado do Rio Grande do Sul, evidenciou que em uma dessas bibliotecas, todos os livros foram classificados na notação 133.9 da CDU. De acordo com o autor, houve ainda casos de os livros serem ordenados alfabeticamente por autor, ou mesmo por título. Furtado (2001) identificou, ainda, que tais práticas eram realizadas na maioria dos Centros Espíritas do Rio Grande que possuíam bibliotecas, ocorrendo em seis dos sete centros pesquisados. A situação ocorre devido à ausência de cobertura do assunto na CDD. Os SOC não deveriam excluir os conhecimentos, mas sim agregá-los, oferecendo espaço de representação.

Identificou-se que o Espiritismo já possui seu próprio esquema de classificação, a Classificação Decimal Espírita, elaborada por Geraldo Campetti Sobrinho (2013) em seu livro "Biblioteca espírita: princípios e técnicas de organização e funcionamento". Esse esquema de classificação abarca o universo do conhecimento espírita. E ainda traz exemplos com as publicações da Federação Espírita Brasileira (FEB). Contudo, ainda se faz necessário que este conhecimento seja devidamente representado na CDD, que segundo a OCLC (2019) é o esquema de classificação mais utilizado no mundo. A Doutrina Espírita, como oitava maior religião do mundo, deve estar mais presente, ocupar mais espaço notacional na CDD.

Com relação à certa falta de isenção existente nos SOC, Milani e Guimarães (2014) também se preocuparam em trazer a questão da não neutralidade dos SOC conforme é observado no trecho a seguir, no qual os autores tratam do prejuízo causado pela "tendenciosidade"

É sabido que cada sistema de classificação, lista de cabeçalhos de assunto ou tesauro será construído e revisado de acordo com os valores de uma época, os objetivos da instituição e as crenças dos envolvidos nesse processo. Por esse motivo, todos esses sistemas de organização do conhecimento são tendenciosos de alguma maneira, mesmo que tenham sido criados com o objetivo único de gerenciar ou organizar livros nas prateleiras, por exemplo. Ocorre que, na literatura especializada de Biblioteconomia e Ciência da Informação, geralmente, considera-se que um sistema de organização do conhecimento é tendencioso quando as nuances que ele destaca causa danos ou benefícios a comunidades de usuários. Na maioria das vezes, a literatura especializada discute os prejuízos causados a alguma dessas comunidades (MILANI; GUIMARÃES, 2014, p. 177).

Outro exemplo a ser tratado, a partir de Miranda (2007) é a questão da falta de representação do etnoconhecimento, pois

O uso da CDD provoca a dispersão semântica da informação relativa ao etnoconhecimento. No tocante ao conhecimento e à cultura afrodescendente, a organização do conhecimento na CDD é imprecisa, não possibilitando identificar as relações etnoconceituais tal como elas se estabelecem na mente dos sujeitos cognoscentes no momento da recuperação da informação (MIRANDA, 2007, p. 10). 
Contudo, os SOC não são neutros, pois são elaborados por pessoas, que também não são neutras e essa falta de neutralidade desses instrumentos que servem como base para a representação do conhecimento, faz por vezes com que determinados assuntos sejam excluídos, ou não considerados em sua totalidade.

Assim, além desta introdução, o artigo aborda a fundamentação teórica, utilizando a teoria de Brougthon (2000) para religião, compreendendo a análise de propostas de expansão de esquemas de classificação efetivadas. Discute classificação e notação a partir de Piedade (1983), trata do Espiritismo, sua breve história, tanto no mundo quanto no Brasil, com o objetivo de demonstrar a história e a importância da Doutrina. Apresenta o Espiritismo e a Classificação Decimal de Dewey, a fim de demonstrar que o Espiritismo não é devidamente representado pelo esquema de classificação de Dewey e, utiliza a teoria de Barité (1990) quanto às modificações em esquemas de classificação, abrangendo a CDD e a CDU.

Na proposta de expansão da classe 202 para o Espiritismo, na qual todos os conceitos mapeados são dispostos de modo a formar um esquema de classificação seguindo os moldes da CDD, esquema no qual pretende ser inserido.

\section{FUNDAMENTAÇÃO TEÓRICA}

A fundamentação teórica consistiu na consulta a artigos sobre a temática de expansão de classificações bibliográficas e a materiais que tratassem do assunto de classificação propriamente dito. Está dividida em duas subseções, a primeira sobre análise de propostas de expansão já criadas, com base na no artigo "Linguagens documentárias e os sistemas de classificação bibliográfica: estudo de propostas de expansão e ampliação da cdd e da cdu" de Tabosa, Cardoso e Albuquerque (2015). A segunda subseção apresenta conceitos de classificação e notação. O objetivo da seção três de fundamentação teórica é tratar temas relacionados a propostas de expansão, visto que o objetivo da pesquisa é uma proposta de expansão da CDD. Desse modo, assuntos como classificação, notação e outros exemplos de propostas já realizadas não poderiam deixar de ser tratados.

O modelo conceitual de classificação que guiou a pesquisa foi elaborado por Brougthon (2000) no qual propõe a seguinte divisão:

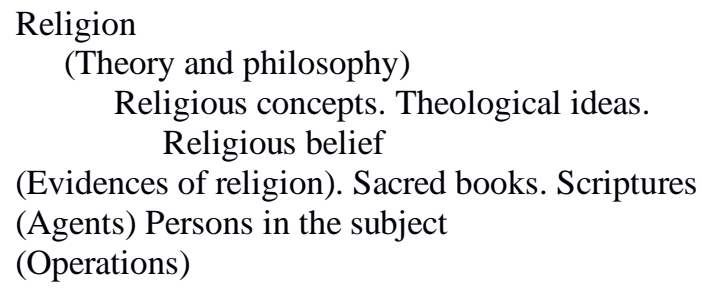




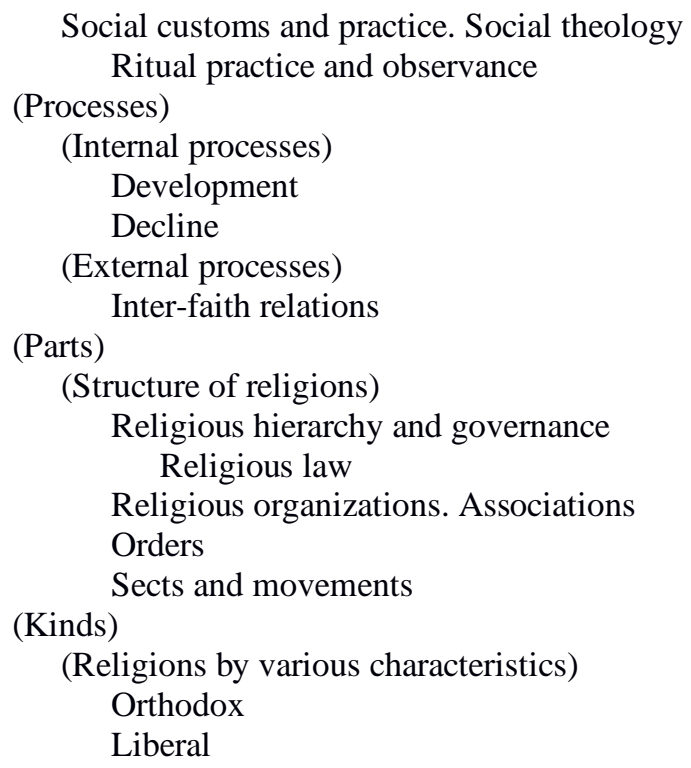

(Systems). Specific religions and faiths (BROUGTHON, 2000, p. 4-5).

Devido ao fato de o Espiritismo não se configurar exatamente como uma religião, mas sim como uma Doutrina, não foi possível utilizar todas as classes de Brougthon, que são para o domínio da religião. Mas como Doutrina, o Espiritismo se adequa em crer em Deus, ter uma data de criação, 1857, ter um criador, no caso um Codificador, Allan Kardec, ter livros que o orientam, o Pentateuco Espirita que é composto pelas obras da Codificação de Kardec, sendo elas: O Livro dos Espíritos (1857), O Livros dos Médiuns (1861), O Evangelho segundo o Espiritismo (1864), O Céu e o Inferno (1865) e A Gênese (1868).

A Doutrina possui a faceta filosofia do Espiritismo, na qual são trabalhados temas relacionados às leis morais. Os conceitos e crenças da Doutrina Espírita estão no fato de crer na existência de espíritos, suas organizações são o Conselho Espírita Internacional e as Federações Espíritas Nacionais, os locais nos quais são realizados os encontros e estudos espíritas são os chamados Centros Espíritas, as práticas podem ser consideradas o passe e a reunião mediúnica. O desenvolvimento da Doutrina ocorreu durante o século XIX, com a Codificação das mensagens dos Espíritos por Kardec. Nesse sentido, foi possível adequar alguns dos conceitos do Espiritismo à teoria de Brougthon (2000), que apesar de ser uma Doutrina, possui os aspectos citados acima.

Contudo, para adequar a Doutrina Espírita à teoria proposta por Brougthon (2000), foi necessário incluir as facetas filosofia, ciência e a própria religião, visto que o Espiritismo possui esse tripé que constitui seu universo do conhecimento. De acordo com Kardec (2008b), o Codificador da Doutrina Espírita:

O Espiritismo é, ao mesmo tempo, uma ciência de observação e uma doutrina filosófica. Como ciência prática ele consiste nas relações estabelecem entre nós e os 
espíritos; como filosofia, compreende todas as consequências morais que dimanam dessas mesmas relações (KARDEC, 2008b, p. 29).

O Espiritismo repudia, nos limites do que lhe pertence, todo efeito maravilhoso, isto é, fora das leis da Natureza; ele não faz milagres nem prodígios, antes explica, em virtude de uma dessas leis, certos efeitos, demonstrando, assim, a sua possibilidade. Ele amplia, igualmente, o domínio da Ciência, e é nisto que ele próprio se torna uma ciência; como, porém, a descoberta dessa nova lei traz consequências morais, o código das consequências faz dele, ao mesmo tempo, uma doutrina filosófica (KARDEC, 2008b, p. 45).

Quanto à faceta religião, Kardec explica que a aversão da igreja para com a nova Doutrina, acabou por torná-la uma nova religião, por conferir-lhe tal status devendo ser combatida com tal:

Em resumo, a Igreja, repelindo sistematicamente os espíritas que a buscavam, forçouos a retroceder; pela natureza e violência dos seus ataques ela ampliou a discussão e conduziu--a para um terreno novo. O Espiritismo era apenas uma simples doutrina filosófica; foi a Igreja quem lhe deu maiores proporções, apresentando--o como inimigo formidável; foi ela, enfim, quem o proclamou nova religião. Foi um passo errado, mas a paixão não raciocina melhor (KARDEC, 2008b, p. 76).

O Espiritismo é ciência quando estuda as relações entre espírito e matéria, é filosofia pois a partir dessas relações trata de assuntos morais que as envolvem e é religião quando traz questões de uma força maior criadora, Deus, do Evangelho e de Jesus, promovendo a transformação moral do homem, sua evolução espiritual.

O processo de coleta de termos ocorreu considerando o endosso do usuário (DODEBEI, 2014), pois vale ressaltar que a co-autora do presente artigo possui conhecimento prévio com relação ao domínio do Espiritismo, ao seu universo do conhecimento, pois a mesma é espiritualista, não deixando de ter de certo modo, o endosso de uma usuária espírita. Considerou-se também a consulta à literatura da área espírita na qual foram retirados os termos que compõe a proposta de expansão. Assim sendo, coleta dos termos foi realizada tendo como base o princípio de endosso do usuário e de consulta à literatura especializada.

Com relação ao estabelecimento do significado dos termos, ou seja, dos conceitos, Dahlberg (1978), na Teoria do Conceito cita que

Podemos agora definir a formação dos conceitos como a reunião e compilação de enunciados verdadeiros a respeito de determinado objeto. Para fixar o resultado dessa compilação necessitamos de um instrumento. Este é constituído pela palavra ou por qualquer signo que possa traduzir e fixar essa compilação. É possível definir, então, o conceito como a compilação de enunciados verdadeiros sobre determinado objeto, fixada por um símbolo linguístico (DAHLBERG, 1978, p. 102).

De acordo com Dodebei (2014, p. 80), a concepção filosófica de conceito o considera como "[...] a essência, a substância das coisas e, ainda, todo o processo que torne possível a descrição, classificação e a previsão dos objetos cognoscíveis. A segunda considera que o 
conceito é um sinal, ou procedimento semántico." As duas autoras citam que conceito é algo que é formulado internamente, no campo do pensamento, que é traduzido por um signo, ou seja, por um termo. Dessa forma, o termo representa o conceito, o traduz. Podendo ter um mesmo termo conceitos diferentes, visto que conceito está no campo das ideias, necessitando de um termo para expressá-lo escrita ou verbalmente.

\subsection{ANÁLISE DE PROPOSTAS DE EXPRESSÃO}

Nos estudos relativos às propostas de expansão de esquemas de classificação destacamse Tabosa, Cardoso e Albuquerque (2015), que estudam quatro modelos de propostas de expansão dentre eles: a Classificação Decimal de Direito (CDDir), da Doris de Queiroz Carvalho (2002), a proposta de expansão da classe de coelhos de raça na CDU, por Tabosa e Cardoso (2011), a proposta de expansão da classe de Direito na CDD, por Mirian Holanda (2002) e a proposta de Albuquerque (2011) para Literatura de Cordel na CDU.

Com relação à expansão de classes, o melhor exemplo prático é a CDDir, elaborada pela bibliotecária e bacharel em Direito Doris de Queiroz Carvalho em 1948, a partir da identificação da necessidade de detalhar a classe 340 de Direito presente na CDD afim de classificar as obras da Biblioteca do Ministério da Fazenda. A expansão preserva a notação da CDD, sua lógica de organização e divide a área do Direito em quatro grandes classes das quais se derivam todas as outras:

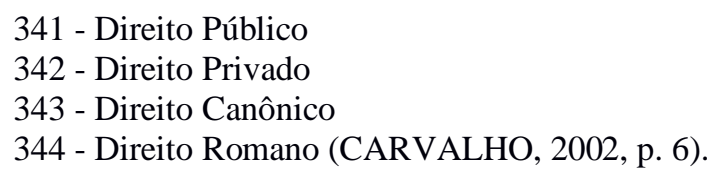

Por manter a notação da CDD e os mesmos princípios de divisão, é possível aplicar a CDDir em bibliotecas que já utilizam a CDD ou a CDU, de modo a melhor especificar e classificar a área do Direito. Atualmente, a CDDir está em sua quarta edição, é amplamente empregada para a classificação de obras de direito e seu acesso é disponível gratuitamente pela internet.

Outro exemplo de proposta de expansão é a de coelhos de raça na CDU, por Tabosa e Cardoso (2011) assunto que sequer é citado no esquema. Os autores utilizaram a classificação de coelhos de raça da American Rabbit Breeders Association, instituição que determina os padrões internacionais de raças de coelhos que já é reconhecida internacionalmente e adequaram-na à notação da CDU. Utilizaram a notação 636.92 na qual já está presente "Coelhos domésticos" e a transformaram para Coelhos de raça, subdividindo em nove classes de acordo 
com oito tipos de raças diferentes, estando a classe 636.929 reservada para coelhos sem raça definida. A partir das oitos classes que comportam oito diferentes raças de coelhos, há diversas subdivisões que cada raça comporta.

Mirian Holanda (2002), bibliotecária do setor Jurídico do Banco do Nordeste do Brasil, também propôs uma expansão da classe do Direito. Sua proposta divide o Direito em nove classes com base na notação 340 da CDD. Entre as classes 340 até 349 a autora engloba assuntos como Direito Constitucional, Civil, Romano, do Trabalho, Tributário, entre outros. E reservou uma classe, a 340 para Direito Geral, compreendendo assuntos que não são englobados pelas classes de 341 a 349.

Por último, Albuquerque (2011), propôs a expansão da classe de Literatura de Cordel nos esquemas de classificação bibliográficas, devido à falta de espaço e representatividade do tema em esquemas como a CDD e a CDU. A autora identificou em sua tese que as Cordeltecas (coleções de folhetos de cordel), eram organizadas alfabeticamente pelo título ou pelo nome do autor, dificultando a recuperação da informação dos cordéis (ALBUQUERQUE, 2011).

Identificado os problemas, Albuquerque (2011) então sugere que sejam criadas vinte e sete classes temáticas para a classificação bibliográfica da Literatura Popular, não incluindo notações nas classes selecionadas, contudo criou mapas conceituais com os termos, pois seu objetivo não era adequar a proposta a um esquema específico como a CDD ou a CDU, mas analisar os temas tratados na literatura popular (ALBUQUERQUE, 2011). A proposta de Albuquerque está em análise pelo comitê do Consórcio da CDU.

Analisado as quatro propostas de expansão de clases, percebe-se que estes tipos de SOC ainda deixam muitas lacunas e acabam por não contemplar diversos assuntos. Preservando a estrutura notacional dos esquemas de classificação que se propuseram a expandir e realizando uma revisão de literatura para coleta dos termos que pudessem vir a compor as propostas de expansão, os autores citados realizaram suas respectivas classificações.

E, com a proposta de expansão do Espiritismo não foi diferente, pois a estrutura lógica e notacional da CDD foi mantida, adequando os termos coletados a partir de uma revisão de literatura realizada em obras da área da Doutrina Espírita, conceituadas e reconhecidas pela FEB, ou mesmo diretamente nas obras de Kardec.

\subsection{CLASSIFICAÇÃO E NOTAÇÃO}

Classificar, de acordo com Piedade (1983, p.16) “[...] é dividir em grupos ou classes, segundo as diferenças e semelhanças. É dispor os conceitos, segundo suas semelhanças e 
diferenças, em certo número de grupos metodicamente distribuídos.” A autora complementa afirmando que se trata de um processo mental inerente ao homem, para que este possa conhecer melhor a realidade.

Langridge (2006, p. 11) também abordou a importância da classificação e afirma que “[...] sem classificação não poderia haver nenhum pensamento humano, ação e organização que conhecemos. A classificação transforma impressões sensoriais isoladas e incoerentes em objetos reconhecíveis e padrões recorríveis."

Barbosa $(1969$, p. 15) comenta que classificar “[...] é na realidade, a tarefa mais importante de uma biblioteca, pois constitui o meio pelo qual os livros são utilizados [...]" e que a classificação em si é “[...] um processo mental pelo qual coisas, seres e pensamento, são reunidos segundo as semelhanças e diferenças que apresentam.” A autora explica que o processo mental é devido ao fato de ser realizado instintivamente, sem que seja necessariamente percebido, pois a ação de classificar é quase que inata aos seres humanos, a todo momento estamos classificando situações, objetos, pessoas e tudo que está ao seu redor.

Para Ranganathan (1967, p. 17), “[...] classificar consiste em traduzir o nome dos assuntos dos documentos da linguagem natural para a linguagem artificial utilizada pelos sistemas de classificação bibliográfica."

Segundo Sayers (1962), a classificação tem quatro significados possíveis são eles:
A) $\mathrm{O}$ processo intelectual pelo qual nossos conceitos mentais [...] são reconhecidos como possuindo semelhança ou unidade, e por esta semelhança ou unidade são relacionados. Este é o sentido real e lógico.
B) $\mathrm{O}$ ato de ordenar as próprias coisas [...] de forma que representem o arranjo abstrato contido no item (a). A tanto monta a classificação prática.
C) A tabela de termos, escrita ou impressa, que representa o sistema de classificação. Chama-se esquema de classificação.
D) $\mathrm{O}$ ato de colocar coisas ou livros em seus lugares apropriados no esquema de classificação. Isto é dispor em classes.

Ou seja, todos os autores citados evidenciam que a classificação é um processo mental inerente ao homem e que no caso dos sistemas bibliográficos o processo é o mesmo, porém realizado de forma artificial, pois é necessário compilar conceitos e organizá-los sistematicamente, configurando-se assim, em uma classificação elaborada com um determinado fim, o de sistematizar o conhecimento de modo a facilitar sua recuperação.

Quanto aos esquemas de classificação bibliográfica, sua principal finalidade é a organização da informação para facilitar sua recuperação por parte dos usuários. De acordo com Piedade (1983, p. 65) seus objetivos são “[...] a ordenação dos documentos nas estantes ou nos arquivos" e "a ordenação das referências bibliográficas ou das fichas no catálogo [...]”, no caso, referindo-se à época dos catálogos de ficha. 
Contudo, no caso específico do esquema criado no presente artigo, a finalidade da proposta de expansão consiste em sistematizar o universo do conhecimento relacionado ao espiritismo, de modo a tornar possível a representação temática da informação para que então, seja viável uma ordenação lógica nas estantes, capaz de fazer com que os usuários recuperem e tenham acesso a esta informação do campo do saber espírita. Fato este que não seria exequível somente com a notação 202 da CDD, visto que não se pode classificar uma biblioteca inteira em uma só classe, pois tal fato dificultaria muito a ordenação das estantes, assim como a recuperação e o acesso à informação.

Ainda conforme Piedade (1983, p. 30) “[...] os sistemas de classificação bibliográfica se baseiam em três conceitos: categorias, divisão lógica (gênero/espécie) e relacionamento.”

Em relação à notação, segundo Piedade (1983, p. 38) "“[...] notação é o conjunto de símbolos destinados a representar os termos da classificação, traduzindo em linguagem codificada o assunto dos documentos, e permitindo sua localização nas estantes, nos catálogos e nas tabelas de classificação.” Bliss (1939), sinalizou a importância de uma notação eficiente, pois segundo o autor uma boa notação não pode tornar um SOC bom, mas o contrário, ou seja, uma má notação é capaz de arruinar um sistema de classificação.

Assim, a notação é parte indispensável de um esquema de classificação, é ela que o representa, que transmite sua lógica de organização e sua finalidade, facilitando “[...] localizar os assuntos na coleção, oferecendo um meio para remeter do índice às tabelas do sistema de classificação [...] além de possibilitar a ordenação dos próprios documentos pelo assunto de que tratam" (PIEDADE, 1983, p. 39).

Para a notação da proposta de expansão foi mantida toda a lógica decimal e hierárquica presente no esquema de Dewey, por se configurar em uma proposta de expansão que possa ser utilizada em bibliotecas que já classificam pela CDD. Adotou-se a notação 202.5 para Espiritismo, estando subordinado a 202 de Doutrina da classe 200 Religião. Dividiu-se o universo do conhecimento espírita em quatro grandes divisões, que possam abranger qualquer assunto da Doutrina em uma delas. Salientando que divisões se configuram como alteração na segunda casa decimal, conforme pode ser evidenciado abaixo, desse modo, assim ficou a cadeia:

200 Religião

202 Doutrina

202.5 Espiritismo

202.51 Aspectos Gerais da Doutrina Espírita

202.52 Religião 


\title{
202.53 Ciência
}

202.54 Filosofia

Em seguida descrevemos o Espiritismo no Brasil e no mundo.

\section{O ESPIRITISMO}

Espiritismo é uma “[...] doutrina fundada sobre a crença na existência dos Espíritos e suas manifestações." (KARDEC, 2010, p. 502). A Doutrina Espírita apresenta-se sob três pilares: ciência, filosofia e religião. O primeiro estuda os aspectos científicos de assuntos como mediunidade, reencarnação e sobre a própria existência do Espírito. A parte filosófica é encarregada de estabelecer as relações com o universo, as leis morais. E a religião que se ocupa da disseminação do Evangelho, seguindo os ensinamentos de Jesus, reconhece a existência de Deus como sendo a causa primeira de toda as coisas (VALENCIA; VOGEL; SILVA, 2016).

De acordo com Kardec, o pilar da Doutrina é a prática da caridade, virtude pregada pelo Codificador nos Centros Espíritas, que "[...] é a alma do Espiritismo, ela resume todos os deveres do homem para consigo mesmo e para com seus semelhantes, razão por que se pode dizer que não há verdadeiro espírita sem caridade.” (CAMPETTI SOBRINHO, 2010, p. 107).

Contudo, cabe fazer uma ressalva, explicando a diferença de Espiritismo e Espiritualismo, conceitos que muitas vezes se confundem no imaginário das pessoas, acreditando serem a mesma coisa. Para fazer esta distinção recorreremos ao próprio Allan Kardec, o Codificador, que em 1857 na introdução do Livro dos Espíritos estabelece a seguinte proposição:

\begin{abstract}
Para se designarem coisas novas são precisos termos novos. Assim o exige a clareza da linguagem, para evitar a confusão inerente à variedade de sentidos das mesmas palavras. Os vocábulos: espiritual, espiritualista, espiritualismo têm acepção bem definida. Dar-lhes outra, para aplicá-los à doutrina dos Espíritos, fora multiplicar as causas já numerosas de anfibologia. Com efeito, o espiritismo é o oposto do materialismo. Quem quer que acredite haver em si alguma coisa mais do que matéria, é espiritualista. Não se segue daí, porém, que creia na existência dos Espíritos ou em suas comunicações com o mundo visível. Em vez das palavras espiritual, espiritualismo, empregamos, para indicar a crença a que vimos de referir- nos, os termos espírita e espiritismo, cuja forma lembra a origem e o sentido radical e que, por isso mesmo, apresentam a vantagem de ser perfeitamente inteligíveis, deixando ao vocábulo espiritualismo a acepção que lhe é própria. Diremos, pois, que a doutrina espírita ou o Espiritismo tem por princípio as relações do mundo material com os Espíritos ou seres do mundo invisível. Os adeptos do Espiritismo serão os espíritas, ou, se quiserem, os espiritistas (KARDEC, 2011b, p.15).
\end{abstract}

Desse modo, os espíritas são os que seguem a Doutrina Espírita, codificada por Kardec, sob a tríade religião, ciência e filosofia, e os espiritualistas são os que creem haver algo a mais que a matéria, mas não necessariamente na Codificação. Kardec, no Livro dos Médiuns (2010), 
cita que todo espírita é espiritualista, por crer em algo a mais que a matéria, mas que nem todo espiritualista é espírita. Ainda acrescenta que no século XIX havia espiritualistas que não acreditavam na seriedade da Doutrina, como pode ser observado no trecho abaixo:

Espiritualismo - Usa-se em sentido oposto ao de materialismo; crença na existência da alma espiritual e imaterial. O espiritualismo é a base de todas as religiões.

Espiritualista - O que se refere ao espiritualismo; adepto do espiritualismo. É espiritualista aquele que acredita que em nós nem tudo é matéria, o que de modo algum implica a crença nas manifestações dos Espíritos. Todo espírita é necessariamente espiritualista; mas, pode-se ser espiritualista sem se ser espírita; o materialista não é uma nem outra coisa. Diz-se: a filosofia espiritualista. - Uma obra escrita segundo as ideias espiritualistas. As manifestações espíritas são produzidas pela ação dos Espíritos sobre a matéria. - A moral espírita decorre do ensino dado pelos Espíritos. - Há espiritualistas que escarnecem das crenças espíritas (KARDEC, 2010, p. 502).

Nas próximas subseções apresentamos de forma breve a história do Espiritismo, a Doutrina no mundo e no Brasil, seu surgimento e em como se tornou o país com maior número de espíritas ao redor do mundo.

\subsection{ESPIRITISMO: UMA BREVE HISTÓRIA}

O espiritismo como Doutrina surgiu a partir da Codificação realizada por Hippolyte Léon Denizard Rivail, sob o pseudônimo de Allan Kardec. O marco inicial ocorreu com o lançamento da primeira edição de "O Livros dos Espíritos", em 1857. Seu desenvolvimento ocorreu a partir de perguntas formuladas por Kardec e enviadas à médiuns por toda Europa, sendo respondidas por meio de psicografia, que consiste na "[...] transmissão do pensamento do Espírito, mediante a escrita feita com a mão do médium.” (CAMPETTI SOBRINHO, 2010, p. 734).

Dessa forma, Kardec desenvolveu um método científico para a elaboração do Livro dos Espíritos, visto que o objetivo de enviar as mesmas perguntas a diversos médiuns em locais diferentes teve o intuito de verificar se as respostas eram as mesmas, evidenciando que foram dadas pelos próprios espíritos e não pelos médiuns que não poderiam responder exatamente a mesma questão se nem se conheciam (MAIOR, 2013).

“O Livro dos Espíritos”, a primeira obra dos cinco livros que compõe a Codificação da Doutrina Espírita, é todo formulado por perguntas e repostas, totalizando 1.019 questões divididas em quatro seções sendo elas "Das causas primárias", "Do mundo espírita ou Mundo dos Espíritos", "Das leis morais" e "Das esperanças e consolações", apresentando a Doutrina sob os aspectos religiosos, científicos e filosóficos (KARDEC, 2011b). 
De acordo com Maior (2013), em apenas dois meses a primeira edição de 1.500 exemplares de "O Livro dos Espíritos" se esgotou, pois havia uma grande curiosidade dos franceses sobre o assunto devido ao fenômeno das "mesas girantes" ter se difundido por todo o país. Eles desejavam respostas para os fenômenos que se espalhavam ao redor da França. Deveria haver algo a mais de explicação sobrenatural. E foi com esse objetivo, de encontrar as respostas que Kardec começou a estudar sistematicamente os fenômenos mediúnicos. Logo no ano seguinte, em 1858, Kardec inaugurou o Círculo Parisiense de Estudos Espíritas, que mais tarde se transformaria na Sociedade Parisiense de Estudos Espíritas, a primeira organização espírita do mundo (MAIOR, 2013).

Depois do Livro dos Espíritos viriam surgir mais quatro livros, compondo assim, o chamado Pentateuco Espírita, os livros bases da Codificação. São eles: "O Livro dos Médiuns" (1861) que trata de questões relacionadas à mediunidade, servindo como guia para quem desejar adentrar no estudo relacionado aos fenômenos mediúnicos, esclarecendo as diversas categorias de mediunidade; "O Evangelho Segundo o Espiritismo" (1864), o qual apresenta a visão espírita do Evangelho de Jesus e da reforma íntima para alcançar a evolução; "O Céu e o Inferno" (1865), trazendo temas relacionados à vida após a morte, como as religiões trabalham o assunto e, posteriormente, apresentando circunstâncias que exemplificam diversas situações de Espíritos diferentes após o desencarne; e "A Gênese" (1868), que versa sobre a origem do planeta Terra, os milagres e as predições (KARDEC, 2006, 2008a, 2010, 2011a).

\subsection{ESPIRITISMO NO MUNDO}

Ao todo existem no mundo cerca de 13,8 milhões de espíritas, ocupando o lugar de oitava maior religião (VILAVERDE, 2016). O Conselho Espírita Internacional (CEI) reúne as federações nacionais de 25 países e cita outros dez que não são filiados ao CEI, mas que possuem organizações espíritas em seu território. Os países que possuem Federações Espíritas Nacionais, de acordo com o CEI, são: Argentina, Alemanha, Bélgica, Bolívia, Brasil, Canadá, Colômbia, Cuba, El Salvador, Espanha, Estados Unidos, França, Guatemala, Holanda, Irlanda, Itália, México, Paraguai, Peru, Portugal, Reino Unido, Suécia, Suíça, Uruguai e Venezuela.

Há ainda os países que não são filiados ao CEI, mas possuem organizações espíritas, sendo eles: Angola, Austrália, Áustria, Chile, Honduras, Luxemburgo, Moçambique, Noruega, Nova Zelândia e Panamá. Totaliza então, 35 países ao redor do mundo. Cabe uma análise, que do total a maior concentração de Federações Espíritas encontra-se nas Américas, contabilizando 17 organizações, seguido da Europa, continente em que surgiu o Espiritismo, com 14. Enquanto 
no continente africano e na Oceania existem somente dois países respectivamente com organizações espíritas. Mas é no Brasil onde há a maior concentração de espíritas no mundo, com a proporção de um em cada três (VILAVERDE, 2016).

\subsection{ESPIRITISMO NO BRASIL}

O surgimento da Doutrina no Brasil ocorreu ainda no século XIX, com a chegada da Codificação de Kardec. Estima-se que o primeiro Centro foi inaugurado na Bahia, em 1865, por Luis Olimpio Teles de Menezes e a tradução do Pentateuco aconteceu em 1875, realizada por Joaquim Carlos Travassos (SCHRÖDER, 2018).

A tradução adotada pela FEB é a de Guillon Ribeiro, que inclusive já foi presidente da Federação. Algumas organizações de estudos espíritas foram criadas no país durante o século XIX, mas a que unificou e permanece ativa até os dias de hoje é a Federação Espírita Brasileira, sendo a instituição responsável por disseminar o estudo e a prática do Espiritismo e foi fundada por Augusto Elias da Silva em 1884 (CAMPETTI SOBRINHO, 2010).

O Brasil foi o país no qual grandes médiuns se desenvolveram, como Bezerra de Menezes e Chico Xavier. Personalidades importantíssimas que ajudaram a disseminar a Doutrina no país. Bezerra de Menezes responsabilizou-se de unir a FEB e duas vertentes do Espiritismo que até então desenvolviam-se de diferentes formas, a científica e a religiosa. Uns acreditavam que o foco deveria ser o estudo científico da Doutrina, enquanto outra parcela pregava que o mais importante era seu caráter religioso e a prática da caridade. O grande médium conseguiu juntar os dois pensamentos (SCHRÖDER, 2018).

Francisco Cândido da Silva Xavier, mais conhecido como Chico Xavier, foi um dos médiuns mais conhecidos do mundo. Psicografou 459 obras e 10 mil cartas. Ajudou muito a disseminar o Espiritismo no país (SCHRÖDER, 2018).

O espiritismo tem no Brasil a maior concentração de adeptos. Encontrou no país grande receptividade aos ideais da Doutrina, adquirindo aqui, um caráter mais religioso, mais até do que na França, local em que ocorreu seu desenvolvimento. A Codificação de Kardec chegou do outro lado do Atlântico por meio dos jornais da época, à exemplo do Courrier du Brésil, que publicava as novidades vindas da França (SCHRÖDER, 2018).

De acordo com o censo realizado pelo IBGE em 2010, o país conta com 3.848 .876 espíritas, configurando-se como a terceira maior religião do Brasil. Segundo os dados da FEB, até o ano de 2012 haviam cerca de 15 mil centros espíritas cadastrados e reconhecidos pela Federação. A maior concentração de seguidores da Doutrina encontra-se no Sudeste, em 
especial no Rio de Janeiro, São Paulo e Minas Gerais, sendo respectivamente, os três estados com maior quantidade de espíritas.

Outra forma de evidenciar a força da Doutrina no Brasil é através da quantidade de livros publicados em português, das produções cinematográficas e em como o assunto é constantemente tratado nas telenovelas. Filmes como "Nosso Lar", do livro homônimo pelo espírito André Luiz, e "Chico Xavier" fizeram muito sucesso no Brasil. Para concluir, um em cada três espíritas no mundo são brasileiros, sendo 3,8 milhões (IBGE, 2010) dentre os 13 milhões de adeptos da Doutrina (VILAVERDE, 2016).

\section{O ESPIRITISMO E A CLASSIFICAÇÃO DECIMAL DE DEWEY}

Na presente seção serão desenvolvidos temas relacionados à CDD e como este esquema de classificação representa o Espiritismo. A primeira subdivisão apresenta uma breve explanação sobre a CDD e sua história, enquanto a segunda traz a questão específica da classe 202, que no esquema representa a Doutrina Espírita.

\subsection{A CLASSIFICAÇÃO DECIMAL DE DEWEY}

A Classificação Decimal de Dewey foi criada por Melvil Dewey, em 1876, configurando-se como "[...] o esquema de classificação bibliográfico mais utilizado e conhecido em todo o mundo." (OCLC, 2019). Teve sua primeira edição composta por 42 páginas, incluindo índice e cerca de 1.000 classes que dividiam o conhecimento humano em dez Main Class, sendo elas:

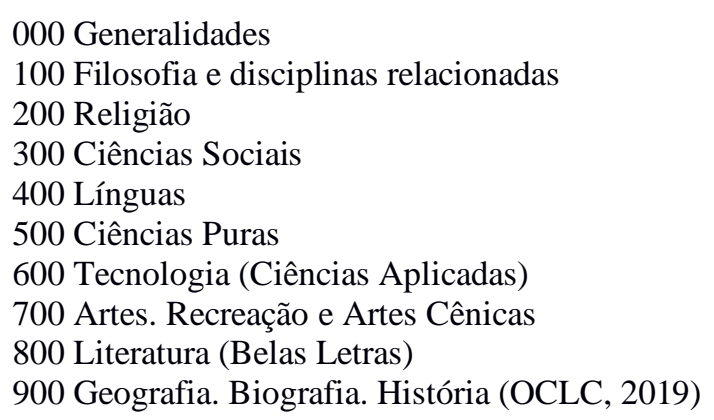

A classe generalidades foi reservada pelo autor para representar obras que tratam sobre diversos assuntos, como enciclopédias, dicionários, entre outros. Acabou sendo destinada para trazer temas como Biblioteconomia, Ciência da Informação, Ciência da Computação, Arquivologia, Jornalismo, entre outros. 
O esquema elaborado por Dewey teve como base os esquemas de classificação de Bacon e Harris, que dividiam todo o conhecimento humano em três grandes categorias - Memória, Imaginação e Razão, das quais derivavam as outras disciplinas. A CDD23 também conta com seis tabelas auxiliares, conforme informações retiradas da WebDewey, sendo a Tabela 1 Standard Subdivisions, subdivisões gerais aplicáveis a todas as classes do esquema, a Tabela 2 relativa à áreas geográficas e períodos históricos, a Tabela 3 divide-se em três (A, B e C) relativas à literatura, autores individuais, gêneros literários e aos trabalhos de autores de literaturas de línguas específicas para serem aplicadas na classe 800, a Tabela 4 relaciona-se à subdivisões de língua, para ser utilizada junto à classe 400, a Tabela 5 apresenta os grupos étnicos, nacionais e raciais e a Tabela 6 as línguas.

As duas últimas podem ser aplicadas em qualquer notação da CDD, desde que haja indicações nas classes principais que permitam a sua inclusão. A CDD23 inclui um extenso índice em seu último volume, contendo todos os conceitos do esquema arranjados alfabeticamente e seguidos da respectiva notação, constituindo um índice relativo, facilitando a localização do conceito desejado.

A CDD atualmente está na sua $23^{a}$ edição, a Online Computer Library Center (OCLC), organização responsável pelo esquema de classificação, a disponibiliza de forma impressa e no site WebDewey mediante assinatura anual. Por meio da WebDewey é possível ter acesso à toda CDD23, realizar pesquisas com o termo que necessita e recuperá-lo exatamente na classe em que se encontra. Este novo mecanismo facilita muito o processo de classificação e foi por meio dele que houve uma satisfatória recuperação com o termo "spiritism", localizado em notas na classe 202 - Doutrina. A iniciativa da OCLC de tornar a CDD disponível on line mostra que a organização está preocupada em tornar o esquema de classificação mais moderno e acessível à atualidade. Tornar as tabelas de Dewey disponíveis em um site e com uma ótima opção de busca foi uma decisão acertada da OCLC.

\subsection{A CLASSE 202}

A CDD reservou a classe 200 para representar todos os assuntos relacionados à Religião, conforme consulta na sua $23^{\mathrm{a}}$ edição disponível na WebDewey. Dentre a citada classe principal está a classe 202, escolhida para englobar as Doutrinas, que não são exatamente definidas como Religião, mas configuram-se como "[...] conjunto de princípios de um sistema religioso, político ou filosófico.” (AMORA, 2008, p. 237). 
O espiritismo aparece em notas dentro da classe 202, conforme verificado na versão WebDewey e na versão online disponível pela OCLC, na qual está escrito "incluindo objetos de adoração e veneração; animismo, espiritismo; humanidade; trabalhos abrangentes sobre carma; escatologia; criação e cosmologia" (OCLC, tradução nossa) contudo não há uma notação própria para o Espiritismo, sua única menção em toda a CDD está em notas. A oitava maior religião do mundo somente é citada em uma nota na classe 202 pelo sistema de organização do conhecimento mais utilizado ao redor do globo.

Ainda sobre a classe Religião e suas subdivisões, a CDD23, versão online disponível pela OCLC, as notações de 220 até 280 representam as Religiões Cristãs, estando todas as demais reservadas somente à classe 290 - Outras religões. Doutrina encontra-se em “Aspectos específicos sobre religião" como pode-se evidenciar no sumário abaixo:

Figura 1 - Classe 200 na CDD23

\section{SUMMARY}

\begin{tabular}{ll}
$\mathbf{2 0 0 . 1 - . 9}$ & \multicolumn{1}{c}{ Standard subdivisions } \\
$\mathbf{2 0 1 - 2 0 9}$ & Specific aspects of religion \\
$\mathbf{2 1 0}$ & Philosophy and theory of religion \\
$\mathbf{2 2 0}$ & Bible \\
$\mathbf{2 3 0}$ & Christianity \\
$\mathbf{2 4 0}$ & Christian moral and devotional theology \\
$\mathbf{2 5 0}$ & Local Christian church and Christian religious orders \\
$\mathbf{2 6 0}$ & Christian social and ecclesiastical theology \\
$\mathbf{2 7 0}$ & History, geographic treatment, biography of Christianity \\
$\mathbf{2 8 0}$ & Denominations and sects of Christian church \\
$\mathbf{2 9 0}$ & Other religions \\
& \\
Fonte: OCLC (2020, online).
\end{tabular}

Essas questões relativas à classe 200 sempre trazem discussões acerca de sua divisão e sobre a falta de representatividade expressiva para diversas religiões, principalmente para as que estão dentre as maiores, com maior quantidade de adeptos no mundo, como é o caso do Islamismo, Budismo, Hinduísmo, e da própria Doutrina Espírita. Como exemplo de discussão com relação à classe 200, Miranda (2007) cita que a CDD dispersa o etnoconhecimento relativos às religiões de matrizes africanas, além de deixá-lo restrito à classe 299.67 Cultos Específicos. Milani e Guimarães (2014) também apontam que os esquemas de classificação são tendenciosos e elaborados de acordo com as ideias da época em que foram criados.

A partir da análise da classe 200 - Religião na CDD23 disponível na WebDewey, em especial na classe 202, que se identificou a necessidade de criação de uma subdivisão própria para o Espiritismo e que estas possíveis novas subclasses possam conter ao menos uma parte de seu universo do conhecimento. 


\section{METODOLOGIA}

A metodologia utilizada no desenvolvimento do presente artigo consiste em uma pesquisa qualitativa e exploratória, pois visa compreender melhor o tema, realizando um levantamento bibliográfico de forma a elucidar os conceitos do Espiritismo, sua criação e como é disseminado ao redor do mundo, especialmente no Brasil. Realiza também uma investigação da classe 202 da CDD23 consultada na WebDewey, intitulada como "Doutrina", dentro da Main Class Religião.

Propõe a partir da escolha dos conceitos da Doutrina Espírita a proposta de expansão da classe Espiritismo, sistematizando-os de modo a formar um esquema de classificação. Por se tratar de uma proposta de expansão, o artigo recorreu à metodologia de modificação de esquemas de classificação, que se fundamenta na teoria de Barité Roqueta (1990) na qual apresenta os tipos de procedimentos metodológicos para modificação de esquemas de classificação como a CDD e a CDU.

Para propor a expansão da classe 202 na qual está representada o Espiritismo, foi necessário a realização de uma revisão bibliográfica nas áreas de classificação e do próprio Espiritismo, de modo que cada termo escolhido para estar na proposta possa ser justificado, pois são validados de acordo com a literatura da área.

Com relação à pesquisa, recorreu-se à Base de Dados em Ciência da Informação (BRAPCI), com a pesquisa dos termos "espiritismo", "espírita” e "expansão" separada. Com a utilização do termo "espiritismo" e "espírita" em pesquisas separadas, recuperou-se o artigo "Tesauro de acervo espírita: uma revisão de tesauro constituído", elaborado por Valencia, Silva e Vogel (2016).

Com a pesquisa do termo "expansão", foram recuperados mais dois artigos: "Linguagens documentárias e os sistemas de classificação bibliográfica: estudo de propostas de expansão e ampliação da CDD e da CDU”, de Tabosa, Cardoso e Albuquerque (2015) e "Proposta de um modelo de expansão da classificação de coelhos de raça na CDU”, por Tabosa e Cardoso (2011). Outro trabalho que merece destaque é a dissertação de PAIVA (2016) "Subsídios para a atualização e/ou expansão colaborativas da Classificação Decimal de Direito - CDDir".

Com relação à metodologia para modificação de esquemas de classificação, utilizou-se a teoria de Barité Roqueta (1990) que indica quatro tipos de procedimentos para reformulação das tabelas da CDD e da CDU, são eles: 
Expansão - são incorporadas e especificadas novas características, novas facetas e subdivisões dos assuntos, se elas forem idealizadas pelo bibliotecário, tendo como fonte um código ou um corpo sistemático de subdivisões externo ao sistema - ou aproveitando subdivisões existentes no próprio sistema;

Atração - opera-se o agrupamento, num dado ponto do sistema, dos diversos aspectos relativos ao mesmo assunto que se encontram dispersos no esquema de classificação;

Integração - procedimento mais generalizado entre os profissionais de classificação quando ocorre a ocupação de notações vagas do sistema por novos assuntos ou conceitos;

Combinação - como o termo denota, dois ou mais procedimentos anteriores são utilizados ao mesmo tempo (BARITÉ ROQUETA, 1990).

Com a análise da metodologia de Barité, pode-se inferir que a proposta de expansão da classe Espiritismo caracteriza-se na categoria "expansão", "integração e "combinação", por utilizar dois procedimentos ao mesmo tempo. Configura-se como expansão por propor novas subdivisões na classe Espiritismo e como integração por utilizar uma notação vaga, a 202.5 para incluir a Doutrina Espírita, transpondo-a de notas da classe 202 e criando uma notação própria para o universo do conhecimento espírita, aproveitando a subclasse vaga.

Contudo, Barité Roqueta (1990) ressalta que se tenha cuidado durante a aplicação do procedimento citado e que os novos conceitos “[...] sejam inseridos no campo de conhecimento que corresponda naturalmente ao objetivo da integração [...]", exatamente o que está sendo realizado ao propor uma nova classe e sua expansão na presente pesquisa, pois a Doutrina Espírita será inserida na classe já pertencente ao assunto Doutrina e na qual é citada em notas, não causando a desestruturação da CDD.

E, a partir da criação da subclasse 202.5 para Espiritismo que ocorre a expansão da CDD, trazendo conceitos novos, novas características que não estão inseridas no esquema, com a consulta à literatura especializada da área que está sendo proposta a expansão. O esquema também compreende o procedimento de combinação, por aplicar a expansão e a integração ao mesmo tempo a fim de formar a divisão 202.5 e suas subclasses para um novo universo do conhecimento que necessita ser inserido e aprofundado na CDD.

Considerando os três aspectos da Doutrina Espírita conforme é tratado nas obras da Codificação, já sendo citado na segunda subseção, os termos que irão compor a proposta de expansão foram selecionados a partir da pesquisa no artigo intitulado "Tesauro de acervo espírita: uma revisão de tesauro constituído" de Valencia, Vogel e Silva (2016) e na Classificação Decimal Espírita, elaborada por Campetti Sobrinho (2013) do livro "Biblioteca Espírita", publicado pela FEB. 
Já os conceitos dos termos eleitos foram retirados da quarta edição do livro "O Espiritismo de A a Z”, elaborado pela Federação Espírita Brasileira e coordenado por Geraldo Campetti Sobrinho (2013). "O Espiritismo de A a Z" consiste em um glossário de termos espíritas, com todas as definições contidas no glossário tendo sido retiradas das obras espíritas publicadas pela FEB (CAMPETTI SOBRINHO, 2013).

O glossário citado no parágrafo anterior conta com mais de 2.100 vocábulos e aproximadamente 10 mil conceitos retirados de 310 livros publicados pela Federação, sendo as obras mediúnicas e não mediúnicas (CAMPETTI SOBRINHO, 2011), mas para utilização na presente pesquisa, foram selecionados somente 45 conceitos retirados do glossário " $\mathrm{O}$ Espiritismo de A a Z".

Na próxima seção apresentamos a análise de cada termo eleito para compor a proposta de expansão.

\section{PROPOSTA DE EXPANSÃO DA CLASSE 202 PARA O ESPIRITISMO}

Após ter coletado os termos do tesauro espírita e as definições do glossário Espiritismo de A a Z, foi possível sistematizar os conceitos em forma de esquema classificação, utilizando os princípios da CDD, como os princípios da hierarquia e da coordenação, ou seja, de cadeias e renques já utilizados na CDD, pode-se construir a proposta de expansão.

Para tal, foi necessário considerar os três aspectos da Doutrina Espírita, o de religião, ciência e filosofia. E ainda relacionar conceitos comuns às três facetas como o Codificador, Allan Kardec, o Pentateuco Espírita, estudo e história da Doutrina, os romances espíritas, os Centros - locais em que ocorrem as reuniões, e as Federações Nacionais. Para incluir tais conceitos citados acima, identificou-se a necessidade de criação de uma subclasse que englobasse todos os termos, desse modo surgiu o "Aspectos gerais da Doutrina Espírita”, que está no mesmo nível hierárquico das subdivisões "Religião", "Ciência" e "Filosofia”, conforme apresentado no quadro 1, p. 47.

Lembrando que a notação 202.5 deve-se ao fato de estar subordinado à classe 202 de Doutrina na CDD e o “.5” porque as notações de.1 até.4 já estão preenchidas no esquema, como pode-se constatar abaixo, através da imagem retirada da WebDewey: 
Figura 2 - Subdivisões da classe 202

\begin{tabular}{|c|c|c|}
\hline \multicolumn{3}{|c|}{ Doctrines } \\
\hline s & $\underline{202.082}$ & Feminist theology \\
\hline .4. & $\underline{202.089 / 96}$ & Black theology \\
\hline ta & $\underline{202.092}$ & Theologians \\
\hline & $\underline{202 / .1} \nabla$ & Objects of worship and veneration \\
\hline & $\underline{2021.2}$ & Humankind \\
\hline & $\underline{202 / .3} \nabla$ & Eschatology \\
\hline & $\underline{202 / .4}$ & Creation and cosmology \\
\hline
\end{tabular}

Fonte: (ONLINE...,2019).

Desse modo, utilizou-se a subclasse 202.5 para transpor o Espiritismo de notas e criar uma notação que pudesse abranger mais subdivisões. A exemplo de 202.51 Aspectos gerais da Doutrina Espírita, 202.52 Religião, 202.53 Ciência e 202.54 Filosofia. E ainda há espaço vago nas subclasses 202.55 até 202.59 que não foram ocupadas, podendo encaixar mais assuntos ou questões novas que possam vir a surgir, respeitando assim, o princípio da hospitalidade (Piedade, 1983).

Considerou-se a reserva de um espaço na notação afim de compreender as subdivisões da Tabela 1 da CDD, a Standard Subdivisions, de modo que possa englobar assuntos como dicionário espírita, enciclopédia espírita, entre outros. A Standard Subdivisions

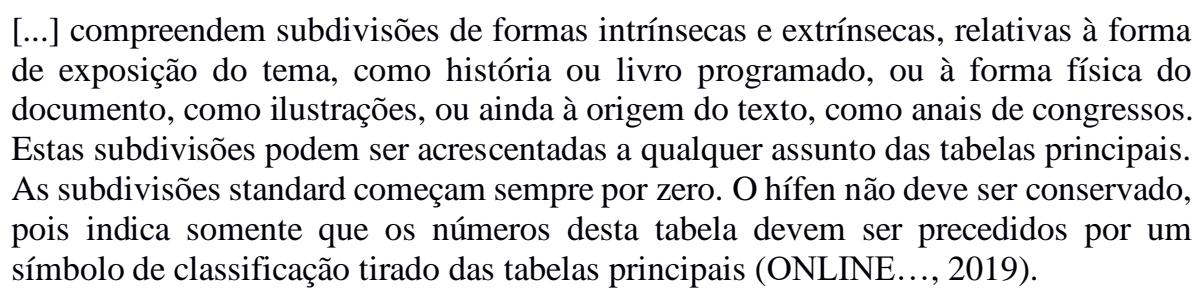

Como é bastante comum nas classes do esquema de Dewey a separação da notação iniciada com o número zero para a Tabela 1, tal regra não poderia deixar de ser aplicada na proposta de expansão. Assim sendo, as notações de 202.501 até 202.509 estão reservadas para as Standard Subdivisions.

\section{Expansão no Esquema de Classificação:}

\subsection{Espiritismo}

$.501-509$ [Standard Subdvisions]

.51 Aspectos gerais da Doutrina Espírita

.511 Allan Kardec

.512 Codificação da Doutrina

.5121 Pentateuco Espírita

.51211 O Livro dos Espíritos

.51212 O Livro dos Médiuns 
.51213 O Evangelho segundo o Espiritismo

.51214 O Céu e o Inferno

.51215 A Gênese

.513 História do Espiritismo

.514 Estudo Sistematizado da Doutrina Espírita

.515 Conselho Espírita Internacional

.5151 Federações Espíritas Nacionais

.516 Centro Espírita

.517 Romance espírita

.518 Espírita

.52 Religião

.521 Deus

.522 Evangelho

.523 Caridade

.524 Evolução espiritual

.5241 Autoconhecimento

.5242 Reforma íntima

.53 Ciência

.531 Mediunidade

.5311 Educação mediúnica

.5312 Comunicação mediúnica

.5313 Médium

.532 Formação do indivíduo

.5321 Espírito

.5322 Alma

.5323 Duplo etérico

.5324 Perispírito

.5325 Corpo físico

.533 Vida espiritual

.5331 Reencarnação

.5332 Plano espiritual

.5333 Umbral

.534 Éter

.535 Obsessão

.536 Passe

\section{.54 Filosofia}

.541 Leis morais

Ao final da proposta de expansão gostaríamos de expressar que o esquema não pretende ser exaustivo, ou seja, compreender todos os conceitos do universo do conhecimento espírita, mas sim elucidar seus principais termos, a fim de possibilitar a recuperação da informação de itens de acervos espíritas, viabilizando seu acesso para os usuários.

\section{CONSIDERAÇÕES FINAIS}

Com o exposto nas seções anteriores do presente artigo, foi evidenciado que o Espiritismo necessita não somente de uma classe própria, como também de uma subdivisão que 
compreenda seu vasto universo do conhecimento, visto que uma doutrina com tamanha quantidade de adeptos e vasta produção literária não pode ter sua representação restrita à uma nota na classe 200. Poder ser devidamente representada no esquema de classificação mais utilizado no mundo demonstra a importância de sua crença e satisfaz as necessidades de busca informacional de seus usuários, dos adeptos da Doutrina Espírita.

Espera-se que a criação da expansão na Classificação Decimal de Dewey possibilite que o próprio esquema seja revisto, representando melhor as diversas religiões existentes no mundo, que carecem de mais espaço no esquema. Restringir a classe 200 à maioria das religiões cristãs, deixando as chamadas “Outras religiões” à margem na classe 290 é restringir o conhecimento, sua representação e seu acesso. O SOC mais utilizado no mundo necessita ser revisto no que tange a representação do conhecimento relativo às religiões.

Pretende-se que a expansão proposta possa ajudar a satisfazer as necessidades informacionais dos usuários espíritas ou dos que somente desejam conhecer a Doutrina, fazendo com que a produção literária espírita possa ser classificada para além da notação 133.9 da CDU ou 202 da CDD, visto não ser possível classificar todo um acervo em uma única notação.

Para concluir, a Classificação Decimal de Dewey ainda é falha ao representar religiões não cristãs, mas que estão dentre as com maiores números de adeptos no mundo, identificando a necessidade de revisão da classe 200 - Religião, a fim de que esta possa contemplar de modo mais igualitário as diversas manifestações religiosas, sejam elas cristãs ou não, existentes ao redor do mundo, principalmente as que possuem grande quantidade de seguidores.

Dessa forma, um esquema de classificação não pode simplesmente excluir todo um universo do conhecimento, fazendo com que a recuperação da informação para os usuários adeptos de tais religiões seja dificultada e colocando suas necessidades informacionais à margem pela falta de representação e de espaço no esquema.

Conseguir um espaço maior na Classificação Decimal de Dewey significa ter a ampla visibilidade de uma religião, possibilitando a recuperação da informação e o acesso em qualquer biblioteca que utilize tal esquema de classificação. Estudiosos da área de Biblioteconomia e Ciência da Informação devem se ocupar dos temas relacionados à representatividade nos sistemas de organização do conhecimento afim de torná-los cada vez mais igualitários e por conseguinte, tornando a representação da informação mais social, facilitando seu acesso a todos os usuários, sem quaisquer distinções, e no tocante ao tema da presente pesquisa, sem distinção de crença religiosa. 


\section{REFERÊNCIAS}

ALBUQUERQUE, Maria Elisabeth Baltar Carneiro de. Literatura popular de cordel: dos ciclos temáticos à classificação bibliográfica. 220 f. 2011. Tese (Doutorado em Letras) Universidade Federal da Paraíba, João Pessoa, 2011.

AMORA, Soares. Minidicionário Soares Amora da língua portuguesa. 18. ed. São Paulo: Saraiva, 2008.

BARBOSA, Alice Príncipe. Teoria e prática dos sistemas de classificação bibliográfica. Rio de Janeiro: Instituto Brasileiro de Bibliografia e Documentação, 1969.

BARITÉ ROQUETA, M. Sistemas de organização do conhecimento: uma tipologia atualizada. Informação \& Informação, Londrina, v. 16, n. 2, p. 122-139, 2011.

BERNARDO, André. Como Allan Kardec popularizou o espiritismo no Brasil, o maior país católico do mundo. BBC News Brasil, Rio de Janeiro, abr. 2019. Disponível em: https://www.bbc.com/portuguese/brasil-47751865. Acesso em: 05 jun. 2019.

BLISS, Henry Evelyn. The organization of knowledge in libraries. New York: H. W. Wilson, 1939.

BROUGTHON, Vanda. A new classification for the literature of religion. In: IFLA COUNCIL AND GENERAL CONFERENCE, 66., 2000, Jerusalém, Israel. Annals [...]. Jerusalém: IFLA, 2000.

CAMPPETI SOBRINHO, Geraldo. Biblioteca espírita. 2. ed. Brasília: FEB, 2013.

CAMPPETI SOBRINHO, Geraldo (coord.). O Espiritismo de A a Z. 4. ed. Rio de Janeiro: FEB, 2010.

CONSELHO ESPÍRITA INTERNACIONAL. Países membros. Disponível em: https://ceispiritistcouncil.com/paises-membros/?lang=pt-pt. Acesso em: 03 jun. 2019.

CARVALHO, Doris de Queiroz. Classificação Decimal de Direito. 4. ed. Brasília: Presidência da República, 2002.

DAHLBERG, Ingetraut. Teoria do conceito. Ci. Inf., Rio de Janeiro, v. 7, n. 2, p. 101-107, 1978.

DODEBEI, Vera Lúcia Doyle. Tesauro: linguagem de representação da memória documentária. Rio de Janeiro: Interciência, 2014.

FEDERAÇÃO ESPÍRITA BRASILEIRA. Dúvidas mais frequentes. Disponível em: https://www.febnet.org.br/blog/geral/o-espiritismo/duvidas-mais-frequentes/. Acesso em: 05 jun. 2019.

FURTADO, Dimi Clei da Silva. As bibliotecas espíritas na cidade do Rio Grande: um estudo sobre suas características, serviços e produtos. 2011. 26 f. Trabalho de Conclusão de Curso (Graduação em Biblioteconomia) - Instituto de Ciências Humanas e da Informação, Universidade Federal do Rio Grande, Rio Grande, 2011. 
HOLANDA, Mirian Elizabeth Albuquerque de. Classificação de Direito. 3. ed. Fortaleza: Indexar, 2002.

INSTITUTO BRASILEIRO DE GEOGRAFIA E ESTATÍSTICA. Censo Demográfico 2010. Disponível em: https://www.ibge.gov.br/estatisticas/sociais/populacao/9662-censodemografico-2010.html?edicao=9749\&t=destaques. Acesso em: 04 jun. 2019.

INSTITUO DE DIFUSÃO ESÍRITA DE JUIZ DE FORA. A Doutrina Espírita. Disponível em: http://ide-jf.org.br/a-doutrina-espirita. Acesso em: 06 jun. 2019.

KARDEC, Allan. O Céu e o Inferno. 2. ed. Rio de Janeiro: FEB, 2011a.

KARDEC, Allan. O Evangelho segundo o Espiritismo. 25. ed. Rio de Janeiro: FEB, 2008a.

KARDEC, Allan. A Gênese. Rio de Janeiro: FEB, 2006.

KARDEC, Allan. O Livro dos Espíritos. 14. ed. Rio de Janeiro: FEB, 2011 b.

KARDEC, Allan. O Livro dos Médiuns. 10. ed. Rio de Janeiro: FEB, 2010.

KARDEC, Allan. O que é o Espiritismo: noções elementares do mundo invisível pelas manifestações dos espíritos. Rio de Janeiro: FEB, 2008b.

LANGRIDGE, Derek. Classificação: abordagem para estudantes de biblioteconomia. Rio de Janeiro: Interciência, 2006.

MAIOR, Marcel Souto. Kardec: a biografia. 2. ed. Rio de Janeiro: Record, 2013.

MILANI, Suellen Oliveira; GUIMARÃES, José Augusto Chaves. Problemas relacionados a Biases em Sistemas de Organização do Conhecimento: perspectivas para a Representação de Assunto. Iris - Informação, Memória e Tecnologia, Recife, v. 3, n. especial, p. 72-92, 2014/2017.

MIRANDA, Marcos Luiz Cavalcanti de. A organização do etnoconhecimento: a representação do conhecimento afrodescendente em Religião na CDD. In: ENCONTRO NACIONAL DE PESQUISA EM CIÊNCIA DA INFORMAÇÃO, 8., 2007, Salvador. Anais [...]. Salvador: UFBA, 2007.

MORAES, I. S.; MOREIRA, W. Os conceitos de sistemas de organização do conhecimento e linguagens documentárias: análise de domínio. In: ENCONTRO NACIONAL DE PESQUISA EM CIÊNCIA DA INFORMAÇÃO, 19., 2018, Marília. Anais [...]. Marília: UNESP, 2018.Disponível em: http://hdl.handle.net/20.500.11959/brapci/103667. Acesso em: 18 jun. 2019.

ONLINE COMPUTER LIBRARY CENTER. Religion. In: ONLINE COMPUTER LIBRARY CENTER. Dewey decimal classification and relative index. Disponível em: https://www.oclc.org/content/dam/oclc/webdewey/help/200.pdf. Acesso em: 06 jun. 2019.

ONLINE COMPUTER LIBRARY CENTER. WebDewey. Disponível em: http://dewey.org/webdewey/standardSearch.html. Acesso em: 06 jun. 2019. 
PAIVA, Maria Cristina de. Subsídios para a atualização e/ou expansão colaborativas da Classificação Decimal de Direito - CDDir. 2016. 245 f. Dissertação (Mestrado Profissional em Biblioteconomia) - Programa de Pós-Graduação em Biblioteconomia, Universidade Federal do Estado do Rio de Janeiro, Rio de Janeiro, 2016.

PIEDADE, M. A. Requião. Introdução à teoria da classificação. 2. ed. Rio de Janeiro: Interciência, 1983.

RANGANATHAN, S. R. Prolegomena to library classification. Bombay: Asia Publ. House, 1967.

SAYERS, W. C. B. A manual of classification for librarians and bibliographers. 3rd ed. rev. with some corrections; with illustrations and bibliography. London: Grafton, 1962.

SCHRÖDER, André. Por que o Espiritismo pegou tanto no Brasil. Superinteressante, São Paulo, maio. 2018. Disponível em: https://super.abril.com.br/cultura/por-que-o-espiritismopegou-tanto-no-brasil/. Acesso em: 04 jun. 2019.

SHERA, Jesse H.; EGAN, Margaret E. Catálogo sistemático: princípios básicos e utilização. Brasília: Editora Universidade de Brasília, 1969.

TABOSA, H. R.; CARDOSO, C. C. C. G.; ALBUQUERQUE, M. E. B. C. Linguagens documentárias e os sistemas de classificação bibliográfica: estudo de propostas de expansão e ampliação da CDD e da CDU. Biblionline, v. 11, n. 1, p. 140-157, 2015. Disponível em: http://hdl.handle.net/20.500.11959/brapci/16854. Acesso em: 05 jun. 2019.

TABOSA, H. R.; CARDOSO, C. C. C. G. Proposta de um modelo de expansão da classificação de coelhos de raça na cdu. Biblionline, João Pessoa, v. 7, n. 2, 2011. Disponível em: http://hdl.handle.net/20.500.11959/brapci/16088. Acesso em: 05 jun. 2019.

VALENCIA, M. C. P.; SILVA, V. P.; VOGEL, M. J. M. Tesauro de acervo espírita: uma revisão de tesauro constituído. BIBLOS - Revista do Instituto de Ciências Humanas e da Informação, v. 30, n. 1, p. 104-141, 2016. Disponível em:

http://hdl.handle.net/20.500.11959/brapci/23490. Acesso em: 05 jun. 2019.

VILAVERDE, Carolina. As oito maiores religiões do mundo. Superinteressante, São Paulo, dez. 2016. Disponível em: https://super.abril.com.br/blog/superlistas/as-8-maiores-religioesdo-mundo/. Acesso em: 04 jun. 2019. 